\title{
The Lithuanian Mathematical Society and Mathematical Life in the Country
}

Remigijus Leipus and Eugenijus Manstavičius (both Vilnius University, Lithuania)

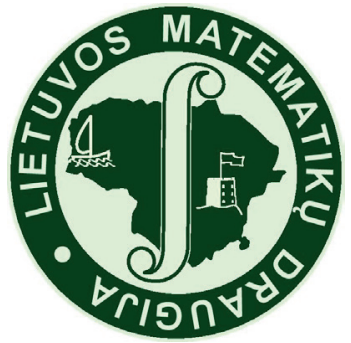

The Lithuanian Mathematical Society (LMS) is a learned society unifying mathematicians - university and college professors, teachers and institute researchers. It varies from 200 to 300 in number. High school teachers, as well as personnel from industrial or business enterprises applying mathematical methods and people generally interested in mathematical knowledge, are likewise warmly welcomed. The LMS aims to develop research in theoretical and applied mathematics, support mathematical education and spread mathematical ideas and knowledge. This short presentation attempts to highlight the Society's activities in achieving these goals. The genesis of the LMS is rather specific; therefore, we deem it worthwhile to present it within the frame of the historical development of education and science in Lithuania.

The emergence of mathematics as a teaching subject in Lithuania traces back to its sixteenth century colleges. The culminating point was the foundation of the Academia et Universitas Vilnensis Societatis Iesu in 1579. Throughout the centuries, the university (sometimes bearing different names, ending up as VU) became a permanent fixture of the country, even if the palmy days were often interrupted by war and oppression. In the first quarter of the nineteenth century, mathematics teaching at VU was of European standard. The three chairs (of pure, applied and elementary mathematics) hosted visiting lecturers; at the same time, the VU enabled its university professors to visit research centres abroad. For example, the manuscripts written by Pranciškus Norvaiša (Narwoysz) during his stay at the University of Nancy have been found there in the library. This advancement come to an end in 1832 when the Russian Tsar closed the Alma Mater. The penalty for the uprising was spot-on: while European science was starting to grow rapidly and the first learned societies were spreading out at European centres, Lithuania was left without a research hearth. After the next deliberation attempt in 1863, the use of the Lithuanian language in official life was forbidden.

The first textbooks in arithmetic and geometry used in the secret Lithuanian schools had to be published in Prussia and transferred through the border at great danger. Soon after the abolition of the Lithuanian press ban in 1907, The Lithuanian Learned Society, containing a few enthusiasts in mathematics, was founded. In the independent state of Lithuania, during 1918-1939, much was undertaken to revive the system of educa- tion. The mathematicians were very active, having joined The Society of Teachers of Mathematics and Physics. In short, the original Lithuanian textbooks in mathematics covered all high school requirements. The first research papers were published by professors of the newly founded university in Kaunas. Professor Otto Folk, who had come from Munich for eight years, was the most active. Here we must recall that the Polish university named after King Stephen Báthory was functioning on the old university premises in Vilnius. The prominent mathematicians Anthony Zygmund and Jozef Marcinkiewicz, to name but a few, were holding lectures there.

The invasion of the Soviets in 1940 and the following deportation of the intelligentsia to Siberia put a halt to this smooth development. The Nazi occupation was no better. Many of the high school teachers and university professors who had survived fled to the West at the end of the war. In the first post-war years, the kernel of teaching staff at the VU comprised of only a few dedicated professors. The rise of the mathematical school and mathematical life in Lithuania is thanks to the efforts of Jonas Kubilius (1921-2011). Soon after the defense of his Candidate of Science Thesis $(=\mathrm{PhD}, 1951$, advisor J.V. Linnik), he returned from Saint Petersburg and took up the lifelong leadership. A vast survey of Kubilius' contributions is the second author's obituary paper in Acta Arithmetica (157.1 (2013), 11-36). Let us outline more of the activities starting in the $1950 \mathrm{~s}$.

Enhancing education and research in mathematics was the main purpose. For younger enthusiasts, the focus was on the annual olympiads, which began in 1952. At universities, the individual work with bright students to attract them to doctoral studies was extended. The most gifted university students were directed to continue their studies in Moscow, Saint Petersburg and Novosibirsk. Implementing Kubilius' idea to concentrate the limited human resources on a few research branches like probability theory and mathematical statistics, a few of the VU graduates were sent to write dissertations in this field. So Vytautas Statulevičius (1929-2003) went to explore the Markov chains in the well-established mathematical schools headed by Linnik and A.N. Kolmogorov, while Bronius Grigelionis (1935-2014) made his first contributions to the theory of random processes in Kyiv under the guidance of B.V. Gnedenko. Later on, both influential Lithuanian mathematicians set up their own research schools.

In the 1950s, regular mathematical seminars and annual conferences by the teaching staff of the VU and researchers from the newly founded (1956) Research Institute of Physics and Mathematics began. That devel- 
oped into the annual national conferences at which the teachers of mathematics were well represented. During the discussions at the first of them, held in 1958, the question about the necessity of a national mathematical society was raised and a working group to arrange its statute was appointed. The foundation of a national professional society in the former Soviet Union was by no means simple. The authorities were only ready to allow the formation of a branch of an all-union society. There was no such mathematical society at that time. Luckily, a short but slightly warmer political period followed. By that time, Kubilius had become a world-renowned scientist, already having written the founding monograph of probabilistic number theory. Witnessing its importance, we recall the following sentence from the review in the Bulletin de la Société Mathematique de Belgique (1967, vol. 19): The work is an epoch-making event in its originality and in the effectiveness of the principle used. Kubilius gained influence in the eyes of the local authorities; in 1958 he was appointed the rector of the VU. Due to the confluence of circumstances, Lithuanian mathematicians were granted their desired society, albeit under the formal patronage of the Lithuanian Academy of Sciences.

On 3 February 1962, the Statute of the LMS was registered. The latest edition of the Statute, accepted in 2014, anchored the LMS as an independent society. The consolidated efforts of the essential base of mathematicians in the country had a great impact. Kubilius was the indispensable president until his death. The authors of this article have had the duty and honour to take over this leadership (Manstavičius from 2011 to 2014, Leipus since 2014).

In the 1960s, the great lack of well-qualified mathematicians was still being felt in the evolving and newly opened institutions. Nevertheless, numerous gifted young scientists matured during this decade. Several young mathematicians with doctoral degrees received from the leading Soviet universities also joined their colleagues in their native country. Apart from research in number theory, probability theory and mathematical statistics, the number of papers in other branches of mathematics, in particular differential equations, numerical mathematics and mathematical modelling significantly increased. It was the LMS who constantly stimulated the collaboration among the research groups. The annual national

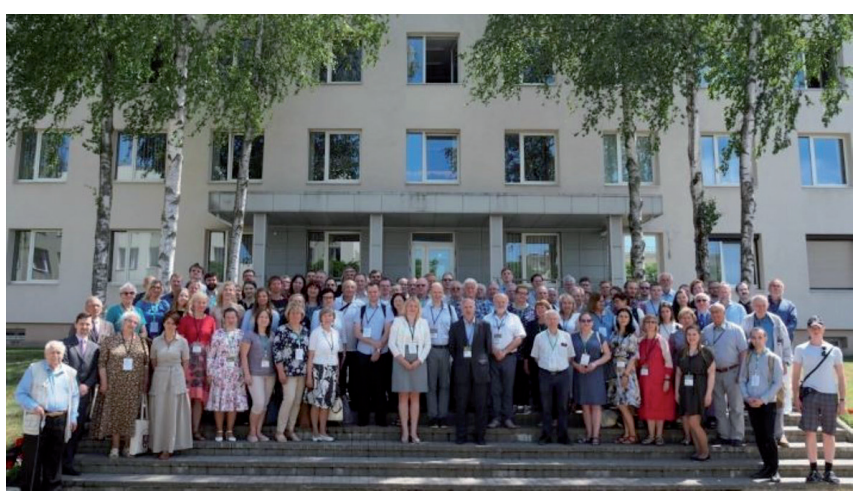

Participants of the 60th LMS Conf. at the General Jonas Žemaitis Military Academy of Lithuania, June 19, 2019. conferences of mathematics were organised at all institutions in a round-robin fashion.

The LMS was one of the founders of the Lithuanian Mathematical Journal (1961). From 1973-2007 the journal was translated by Plenum and Kluwer publishers; since 2008 it has become a Springer edition. Editors-inChief were Petras Katilius, Jonas Kubilius and Mifodijus Sapagovas; since 2008 Vygantas Paulauskas has held this position. In addition, nowadays four international mathematical journals are issued in Lithuania and are seeking prestige. Many international conferences in mathematics have been organised in Lithuania. The LMS has intensified its help to the organisers, in particular, dealing with the fiscal formalities which are very strict in the country. The European Mathematical Society has supported: the 27th Journée Arithmétique (Vilnius, 2011), the 4th, 5th and 6th conf. on number theory dedicated to Kubilius' jubilees (Palanga, 2006, 2011 and 2016); and the 11th and 12th Vilnius' International Conferences on Probability Theory and Mathematical Statistics $(2014,2018)$. The latter was held jointly with the 2018 IMS Annual Meeting. Here, we must pay tribute to Statulevičius and Paulauskas as the former chairmen of the Organising Committees, the first author took command of them in the last few years. The contribution of the co-chairs of the Organising and Program Committees Erwin Bolthausen, Peter Bühlmann and Peter Jagers, as well as of all committee members including our colleagues Mindaugas Bloznelis, Rimas Norvaiša and Donatas Surgailis, to mention but a few, has been greatly appreciated. The 13th Vilnius conference is on the agenda for 2022.

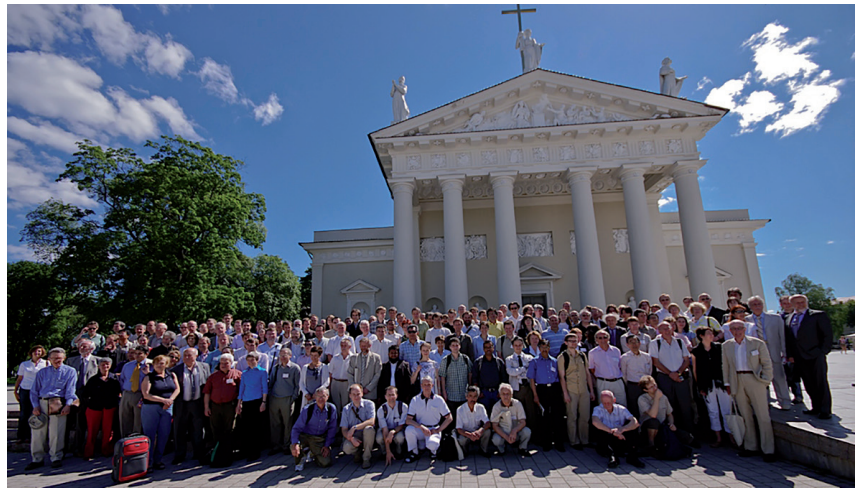

Participants of the Vilnius 10th Conf. at the Cathedral, June 28, 2010.

Attention to the high school problems has not been decreased. Nowadays, the Lithuanian Mathematics Teachers Association (founded in 1991) is a faithful partner of the LMS. Apart from textbooks, many complementary material issues and popular books have been published. Lithuanian school children actively take part in the International Kangaroo Test, in a dozen regional olympiads. The winners of the annual national olympiads comprise the teams taking part in international events such as the Mathematical Contest of Friendship in Honour and Memory of Grand Duchy of Lithuania, the Middle European Mathematical Olympiad and The Baltic Way contest. The achievements at the International Mathematics Olympiad are comparable with that of countries of a similar size. Nevertheless, the lowering 
of the average level at middle schools is causing great concern. The continuing reforms and reduction of the teaching hours devoted to the subject of mathematics as well as the decreasing attention of the authorities and the low prestige of a teacher's position have had a negative influence.

Raising public awareness, the LMS and academic institutions have published several popular books devoted to the memory of praiseworthy personalities or to the history of mathematics in Lithuania. The LMS is ashamed to admit that the popular Mathematical Journal $\alpha+\omega$ (1996-2003, Ed. Vilius Stakenas) has terminated its existence. The most valuable are the activities (since 1983) of the Lithuanian Henrikas Jasiūnas Museum of Mathematicians named after its founder. The reader is welcome to visit its homepage: http://www.matmuziejus. mif.vu.lt/
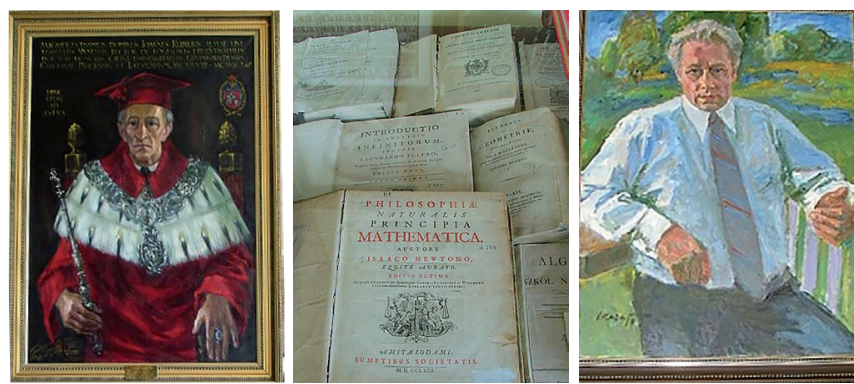

From the Museum exposition; portraits of Kubilius by Vytautas Ciplijauskas and of Statulevičius by Vladas Karatajus.

The research achievements in the field of mathematics have won recognition in Lithuania. This can be witnessed by 12 National Science Prizes won by 22 mathematicians during 1991-2019 and two prestige Kubilius' Prizes of the Lithuanian Academy of Sciences (so far, the grantees were Manstavičius, Paulauskas and Surgailis). For its part, the LMS honours those contributing to science and education in the country by presenting the Zigmas Žemaitis Medal. Recently, the Prize of the LMS for mathematicians not older than 40 has been established. The first laureates were Vytautas Paškūnas (University of Duisburg-Essen), Kęstutis Česnavičius (Université Paris-Sud 11) and Paulius Drungilas (VU). In these times of continuing brain-drain, young Lithuanian students or those who already have positions abroad gather in their native country before New Year's Eve for a multidisciplinary workshop supported by the LMS. In 2019 the 8th one was held. Many of the participants are waiting for greater support from the government's side in terms of increased wages in academic positions.

In the last decade, the LMS has intensified its contact with the EMS by taking part in most of the Euro-
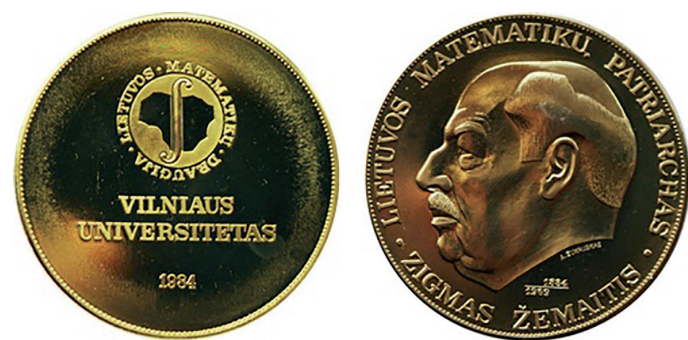

Zigmas Žemaitis Medal

pean events. Recall that Kubilius and Grigelionis signed the founding agreement and happily toasted the genesis of the EMS at the Madralin meeting in 1990. The LMS joined the International Mathematical Union in 1995.

More information can be found on the LMS webpage: http://www.lmd.mif.vu.lt/

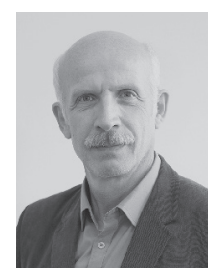

Remigijus Leipus [remigijus.leipus@mif. $v u . l t]$ is professor and director of the Institute of Applied Mathematics at the VU. He has been a president of the LMS since 2014. He has visited many universities throughout the world; in particular, he had a oneyear Fullbright scholarship at Virginia Tech in 1993-1994, worked at the University of Liverpool in 1997-1998 and at the University of Utah in 2005. He collaborates with many partners in USA, France, China, etc. He was a chairman of the recent International Vilnius conferences on Probability Theory and Mathematical Statistics. Research interests lie mainly in probability theory, mathematical statistics and econometrics, since 2014 he is a full member of the Lithuanian Academy of Sciences.

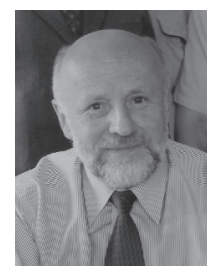

Eugenijus Manstavičius [eugenijus.manstavicius@mif.vu.lt] is a professor emeritus at the VU. He served as president of the LMS from 2011 to 2014. He has held visiting positions at a dozen universities throughout the world; in particular, had a one-year professorship at the Paderborn University, worked on an individual EC project at the University of Bordeaux 1, collaborated with a partner in an NRC Twinning Program project at the Pennsylvania State University. His research interests lie mainly in probabilistic number theory and combinatorics. He is a holder of the National Science Prize of Lithuania and the Kubilius' Prize of the Lithuanian Academy of Sciences, to which he was elected in 2004 as the expert member, and since 2011 he is a full member. 